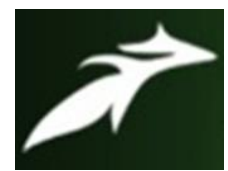

Deeptangshu Sarma et al, International Journal of Advances in Agricultural Science and Technology,

Vol.8 Issue.8, August-2021, pg. 147-162

\title{
To Study the Socio-Economic Status of Small and Marginal Farmers with Special Reference to Schedule Caste and Schedule Tribe Farmers of Kamrup District of Assam
}

\author{
Deeptangshu Sarma \\ Msc Ag (Agriculture Extension and Communication) \\ Prof.(Dr.) Ms. Jahanara \\ (Head Of the Department), Department of Agricultural Extension and Communication, SHUATS, PRAYAGRAJ \\ DOI: 10.47856/ijaast.2021.v08i8.016
}

\begin{abstract}
SES (socio-economic status) is a measurement of an entity's economic and social position in comparison to others in society. It has an impact on resource accessibility, livelihood patterns, food and nutritional security, and so on. Knowledge, attitude, perception, adoption, change-proneness, level of aspiration, economic motivation and other psychological and behavioural components of a sample are frequently predicted. The present study tried to investigate about the socio economic status of the marginal and small farmers with special reference to Schedule caste and schedule tribe farmers in Kamrup district of Assam. Descriptive research design has been used . Data of 120 respondents were collected with the help of pre-structured questionnaire and personal interview. The study was conducted in 5 villages in Kamrup district of Assam in the year 2021.Thirteen variables were selected viz. category Gender, age, caste, education, annual income, occupation, social participation, types of house, land holding, Mass media exposure, farm power, material possessed, Extension contact were taken into account. Equal numbers of respondents were taken from SC and ST. $64.2 \%$ of the respondents were male. Majority of them were under 30 years old. Majority of the percentage had primary level of education, along with medium annual income. The overall SES category was medium level with $48.3 \%$ and low level $32.5 \%$ of SES category, $19.2 \%$ high level.
\end{abstract}

\section{Introduction}

It was 50 years ago, at the time when we got independence, Gandhiji said "India lives in villages, if villages perish India will perish too". It is true even in the year 2021 Indian economy is totally dependent upon agriculture or farming. Almost $70 \%$ of the Indian populations are involved in farming and agriculture based sector. Change is natural phenomenon of all culture. The rate of changes differs from societies to societies especially between modern and primitive society. In advance societies the change occur at faster rate. Societal changes are associated with transformations in various spheres of human life. Many 


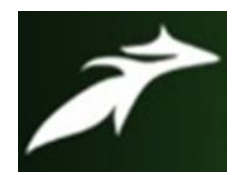

Deeptangshu Sarma et al, International Journal of Advances in Agricultural Science and Technology, Vol.8 Issue.8, August-2021, pg. 147-162

ISSN: 2348-1358

Impact Factor: 6.057

NAAS Rating: 3.77

countries have undergone tremendous changes over recent decades with implications including economic restructuring, changes in societal value systems, the spread of media technology, and changes in educational systems or population composition. SES (socioeconomic status) is an assessment of an individual's or a group's economic and social position in relation to others in society. It plays a significant influence in defining one's access to common resources and livelihood, home food \& nutritional security, and so on. It also directs the psychological and social aspects of life. It also directs the psychological and behavioural components of a sample, such as knowledge, attitude, perception, adoption, changeproneness, aspiration level, risk-taking capacity, economic incentive, and so on. SES is defined by a combination of social and economic factors. The objective and subject of the study heavily influence the choice of these factors under SES. To study of SES of small and marginal farmers is important because, it will give us a clear explanation of status of these farmers and how they spend their livelihood.

\section{Methodology}

Research methodology is the path through which researchers need to conduct their research. It shows the path through which these researchers formulate their problem and objective and present their result from the data obtained during the study period. Purpose of this methodology is to satisfy the research plan and target devised by the researcher.

Descriptive research design will be followed for the analysis.

Descriptive Research Design:- Descriptive research aims to accurately and systematically describe a population, situation or phenomenon. It can answer what, where, when and how questions, but not why questions. A descriptive research design can use a wide variety of research methods to investigate one or more variables.

\section{SAMPLING TECHNIQUE}

Kamrup Rural district of Assam is selected purposively for the present study and also various developmental programs are running there and different social changes have occurred, some of the villages comprises almost $90 \%$ of SC and ST farmers so, this district has been choosen for study. There are 9 blocks in the selected district out of that CHAAYGAON block will be selected purposively because the resource availability and existence of Schedule caste and schedule tribe farmers are more compared to other blocks. There are 58 Revenue villages in the selected block out of that 5 village has been selected namely Batakuchi, Batarapara, Khatalpara, Chakarapani and Kahibama will be selected purposively. 120 Respondents were randomly choosen among the 5 villages. The data was collected from respondents by using the pre structured interview schedule. Data analysis is done through frequency and percentage distribution using statistical tools.

For calculating percentage, frequency was multiplied by 100 and divided by total number of Respondents. $\mathrm{P}=\mathrm{X} / \mathrm{N} \times 100$ Where,

$\mathrm{P}=$ Percentage 


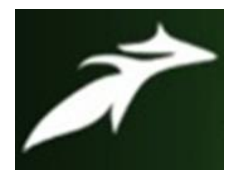

Deeptangshu Sarma et al, International Journal of Advances in Agricultural Science and Technology, Vol.8 Issue.8, August-2021, pg. 147-162

$\mathrm{X}=$ Frequency of the Respondents

$\mathrm{N}=$ Total number of Respondents

Results

To access the socio-economic profile of respondent

\section{Gender}

Distribution of table based on:-

1. Gender

Table 1:- Distribution of respondents based on Gender

\begin{tabular}{|l|l|l|l|}
\hline Sl.No & Gender & Frequency & Percentage \\
\hline 1. & Male & 77 & 64.2 \\
\hline 2. & Female & 43 & 35.8 \\
\hline & Total & 120 & $100 \%$ \\
\hline
\end{tabular}

Fig 1:- Distribution of Respondents based on gender

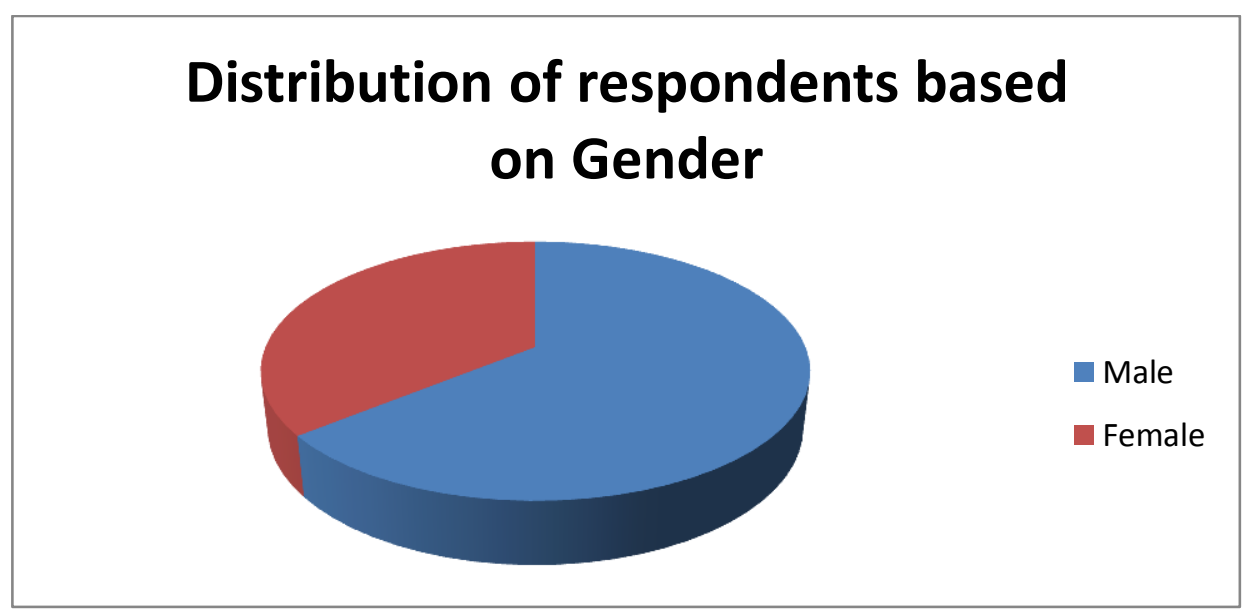

From the above table 1 and Fig 1 it can be observed that the majority of the respondents are male which is $64.2 \%$ and the other respondents are female $35.8 \%$

2. Age

Table 2:- Distribution of respondents based Age

\begin{tabular}{|c|c|c|c|}
\hline Sl.no & Age & Frequency & Percentage \\
\hline 1. & $20-30$ & 61 & $50.8 \%$ \\
\hline 2. & $31-40$ & 32 & $26.7 \%$ \\
\hline 3. & $41-50$ & 17 & $14.2 \%$ \\
\hline 4. & $51-60$ & 10 & $8.3 \%$ \\
\hline & Total & 120 & $100 \%$ \\
\hline
\end{tabular}




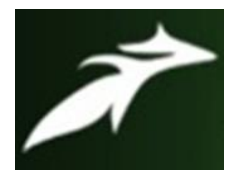

Deeptangshu Sarma et al, International Journal of Advances in Agricultural Science and Technology, Vol.8 Issue.8, August-2021, pg. 147-162

ISSN: 2348-1358

Impact Factor: 6.057

NAAS Rating: 3.77

Fig 2:- Distribution of respondents based on Age

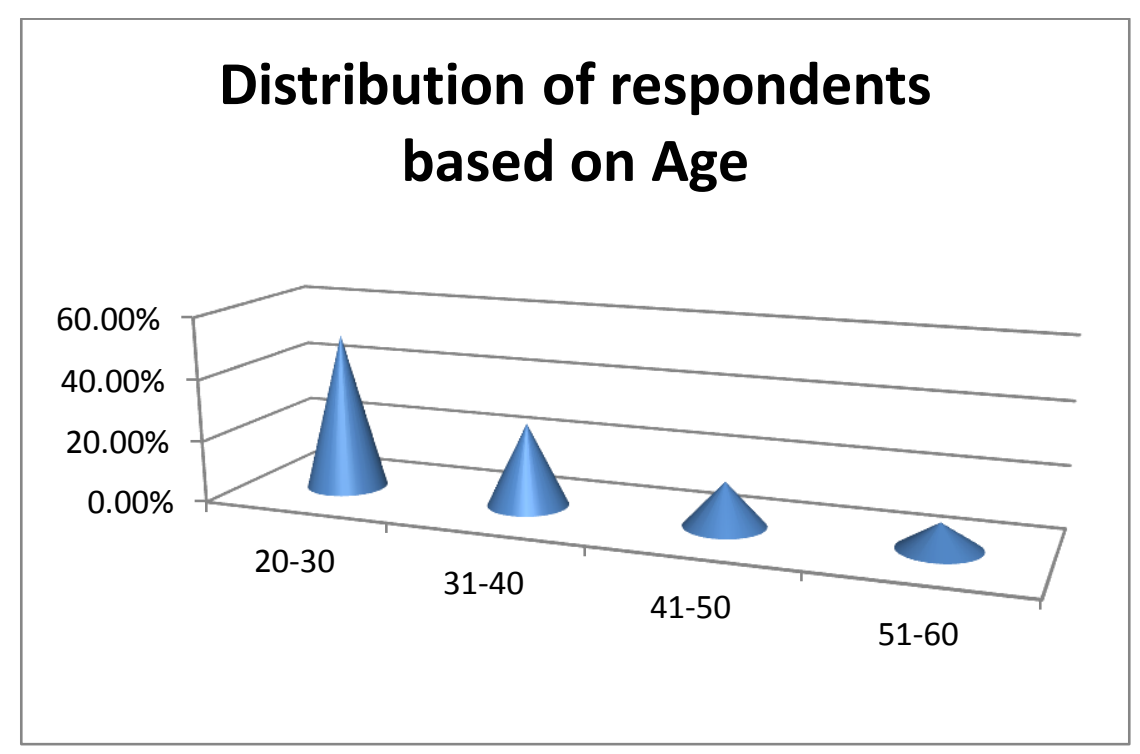

From the above table 2 and Fig:- 2 we can observe that the majority of the respondents $50.8 \%$ fall under the age group of 20-30, while $26.7 \%$ of the respondents fall under 31-40 age group, $14.2 \%$ of the respondents fall under the age group $41-50$ and least number of respondents $8.3 \%$ fall under the age group of 51-60.

\section{Caste}

Table 3:-

\begin{tabular}{|c|c|c|c|}
\hline Sl.no & Caste & Frequency & Percentage \\
\hline 1. & SC & 60 & $50 \%$ \\
\hline 2. & ST & 60 & $50 \%$ \\
\hline & Total & 120 & $100 \%$ \\
\hline
\end{tabular}




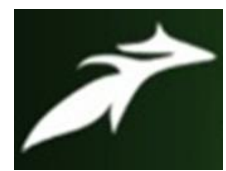

Deeptangshu Sarma et al, International Journal of Advances in Agricultural Science and Technology, Vol.8 Issue.8, August-2021, pg. 147-162

Fig 3:- Distribution of respondents based Caste

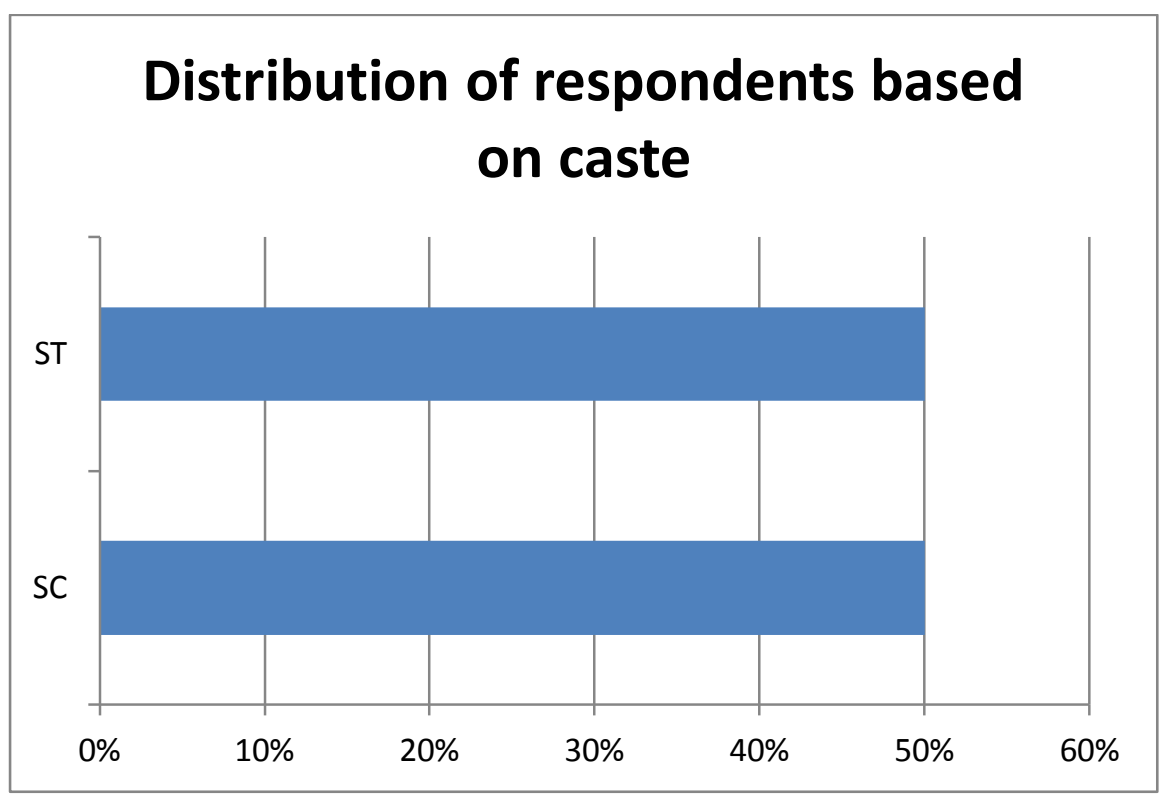

From the above table 3 and fig 3 we can observe that there were equal number of respondents $50 \%$ each were both SC and ST

\section{Education}

Table 4:- Distribution of respondent based Education

\begin{tabular}{|c|c|c|c|}
\hline Sl.no & Education & Frequency & Percentage \\
\hline 1. & Illiterate & 0 & $0 \%$ \\
\hline 2. & Primary & 55 & $45.8 \%$ \\
\hline 3. & High School & 36 & $30 \%$ \\
\hline 4. & $\begin{array}{c}\text { Intermediate High } \\
\text { School }\end{array}$ & 20 & $16.7 \%$ \\
\hline 5. & Graduate & 9 & $7.5 \%$ \\
\hline 6. & Post-Graduate & 0 & $0 \%$ \\
\hline & Total & 120 & $100 \%$ \\
\hline
\end{tabular}




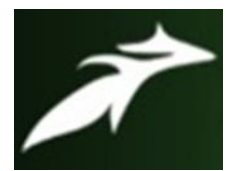

Deeptangshu Sarma et al, International Journal of Advances in Agricultural Science and Technology, Vol.8 Issue.8, August-2021, pg. 147-162

Fig.4- Distribution of respondent based Education

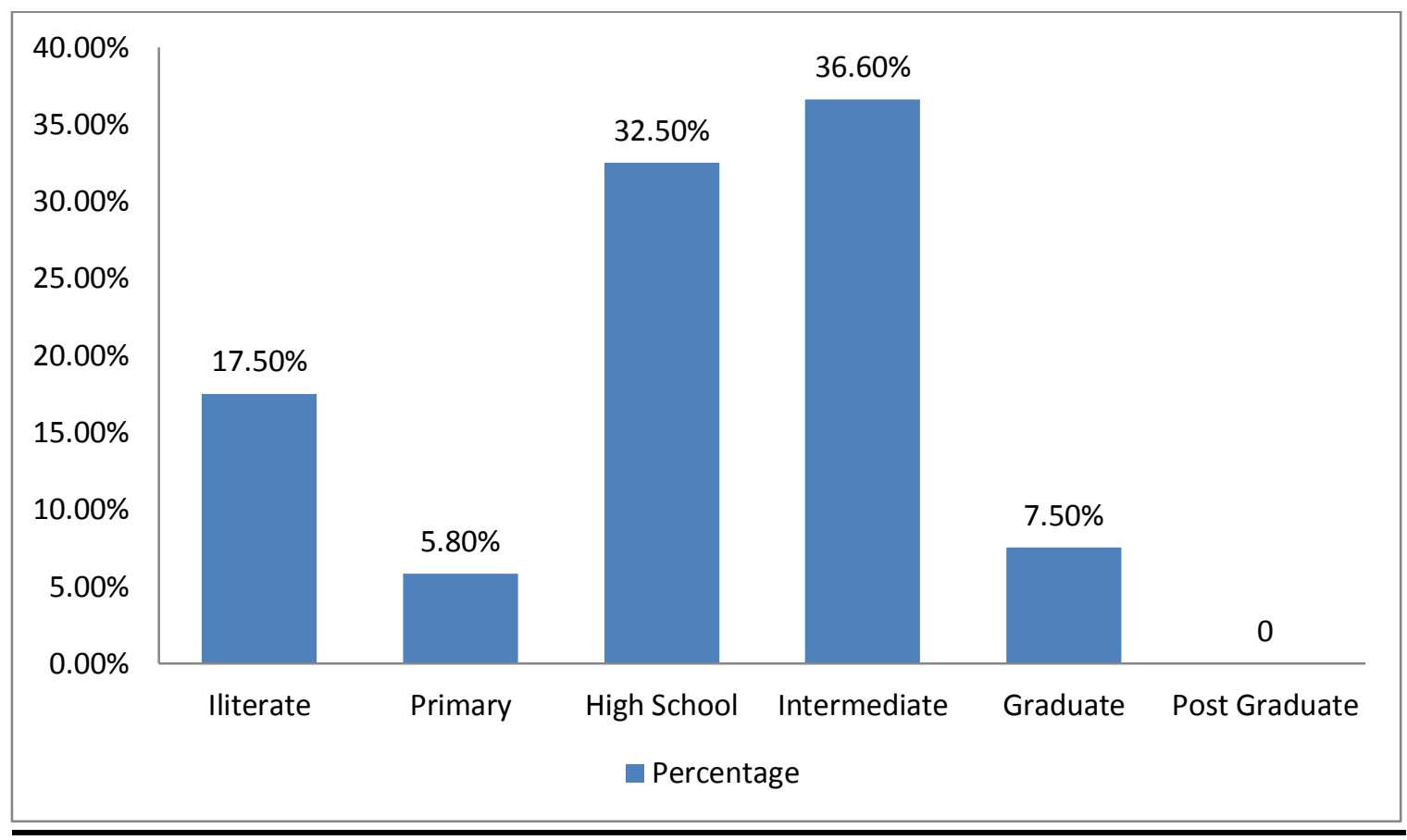

From the above table 4 we can observe that $0 \%$ of the respondents fall under Illiterate category, while $45.8 \%$ has primary education, $30 \%$ of the respondents have attended high school, while a mere $16.7 \%$ have education upto intermediate high shool, and $7.5 \%$ has completed graduation.

\section{Annual Income}

Table 5:- Distribution of respondents based Annual Income

\begin{tabular}{|c|c|c|c|}
\hline Sl.no & Annual Income & Frequency & Percentage \\
\hline 1. & High & 7 & $5.8 \%$ \\
\hline 2. & Medium & 79 & $65.8 \%$ \\
\hline 3. & Low & 34 & $28.4 \%$ \\
\hline & Total & 120 & $100 \%$ \\
\hline
\end{tabular}




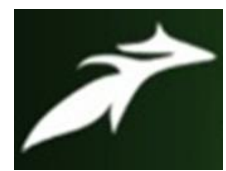

Deeptangshu Sarma et al, International Journal of Advances in Agricultural Science and Technology, Vol.8 Issue.8, August-2021, pg. 147-162

Fig 5:- Distribution of respondents based Annual Income

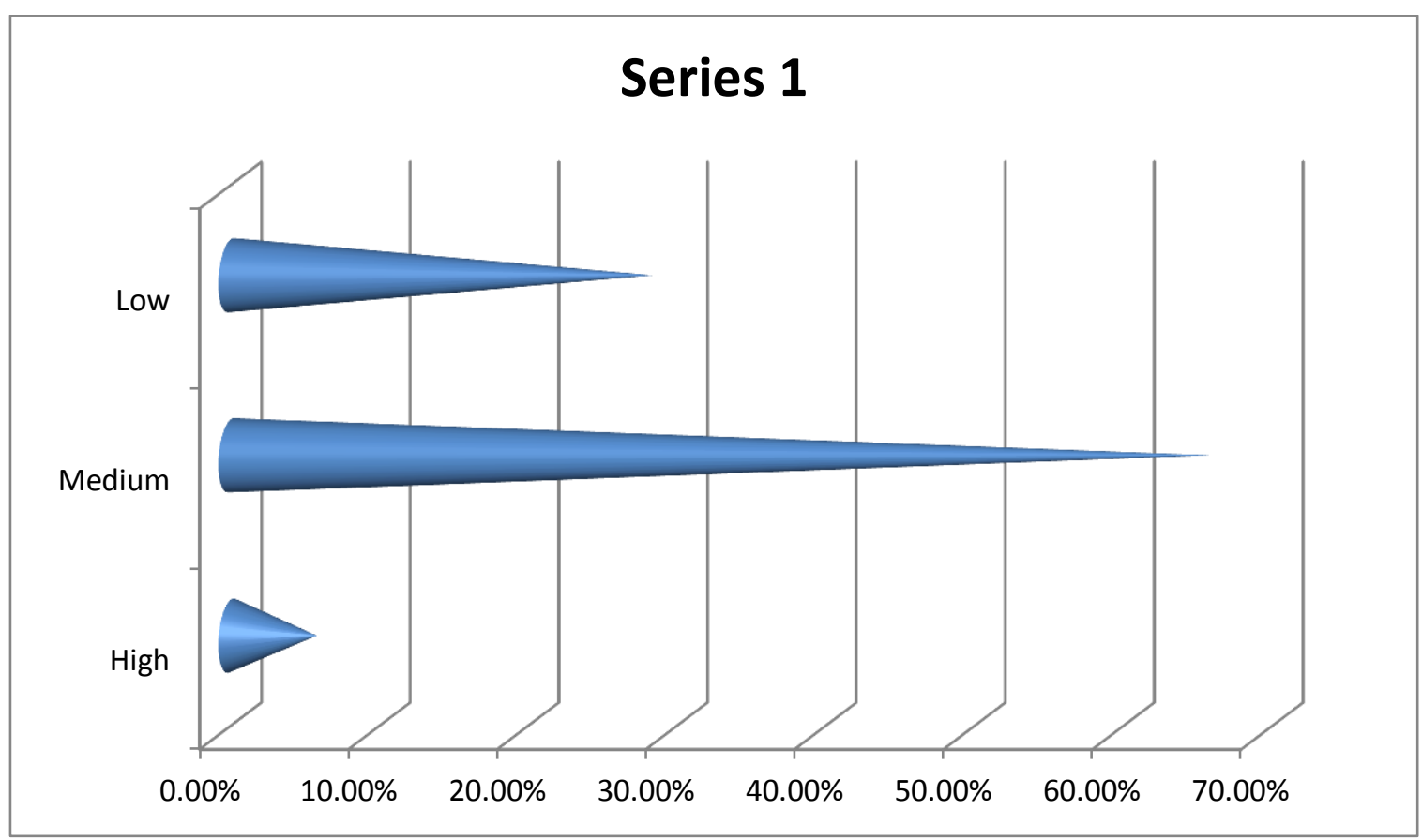

From the above table 5 and fig 5 we can see that $5.8 \%$ of the respondents fall under high income category, $65.8 \%$ which is maximum people fall under medium earning income category, and $28.4 \%$ fall under low category income.

\section{Types of Houses}

Table 6:- Distribution of respondents based on Types houses

\begin{tabular}{|c|c|c|c|}
\hline Sl.no & House Type & Frequency & Percentage \\
\hline 1. & Mud House & 9 & $7.5 \%$ \\
\hline 2. & Semi-cemented & 82 & $68.3 \%$ \\
\hline 3. & Cemented & 29 & $24.1 \%$ \\
\hline & Total & 120 & $100 \%$ \\
\hline
\end{tabular}




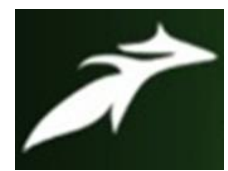

Deeptangshu Sarma et al, International Journal of Advances in Agricultural Science and Technology, Vol.8 Issue.8, August-2021, pg. 147-162

Fig 6:- Distribution of respondents based on Types of houses

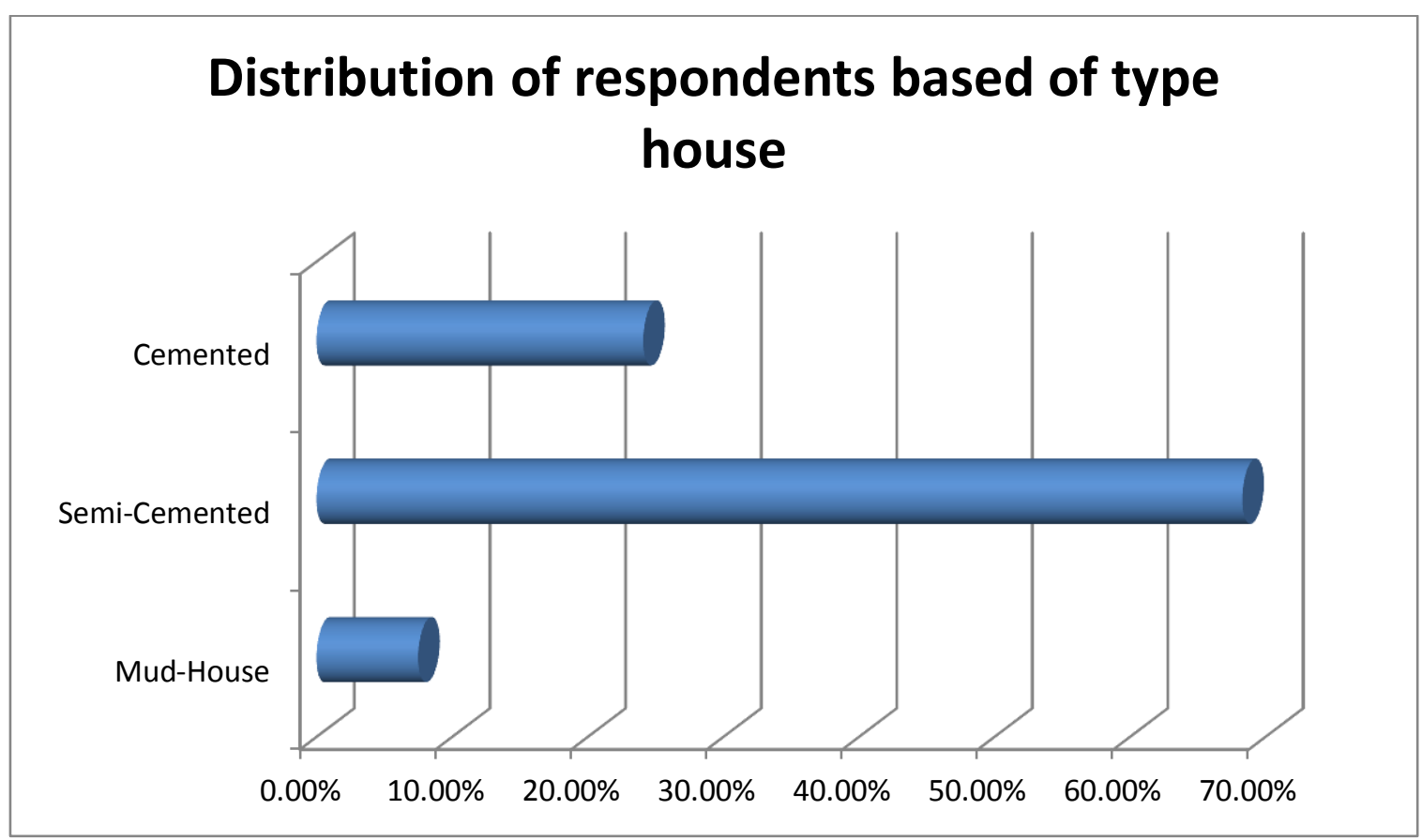

From the table 6 and fig 6 we can conclude that majority of the respondents $68.3 \%$ lives in semi-cemented house, $24.1 \%$ of the respondents live in cemented house whereas $7.5 \%$ of the respondents live in mud house or kaccha house.

\section{Land Holdings}

Table 7:- Distribution of respondents based on land holding

\begin{tabular}{|l|l|l|l|}
\hline S. No & Land holding & Frequency & Percentage \\
\hline 1. & Marginal & 60 & $50 \%$ \\
\hline 2. & Small & 60 & $50 \%$ \\
\hline 3. & Medium & 0 & $0 \%$ \\
\hline 4 & Large & 0 & $0 \%$ \\
\hline & Total & 120 & 100.00 \\
\hline
\end{tabular}




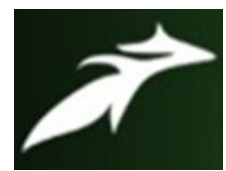

Deeptangshu Sarma et al, International Journal of Advances in Agricultural Science and Technology, Vol.8 Issue.8, August-2021, pg. 147-162

Fig 7:- Distribution of respondents based on land holding

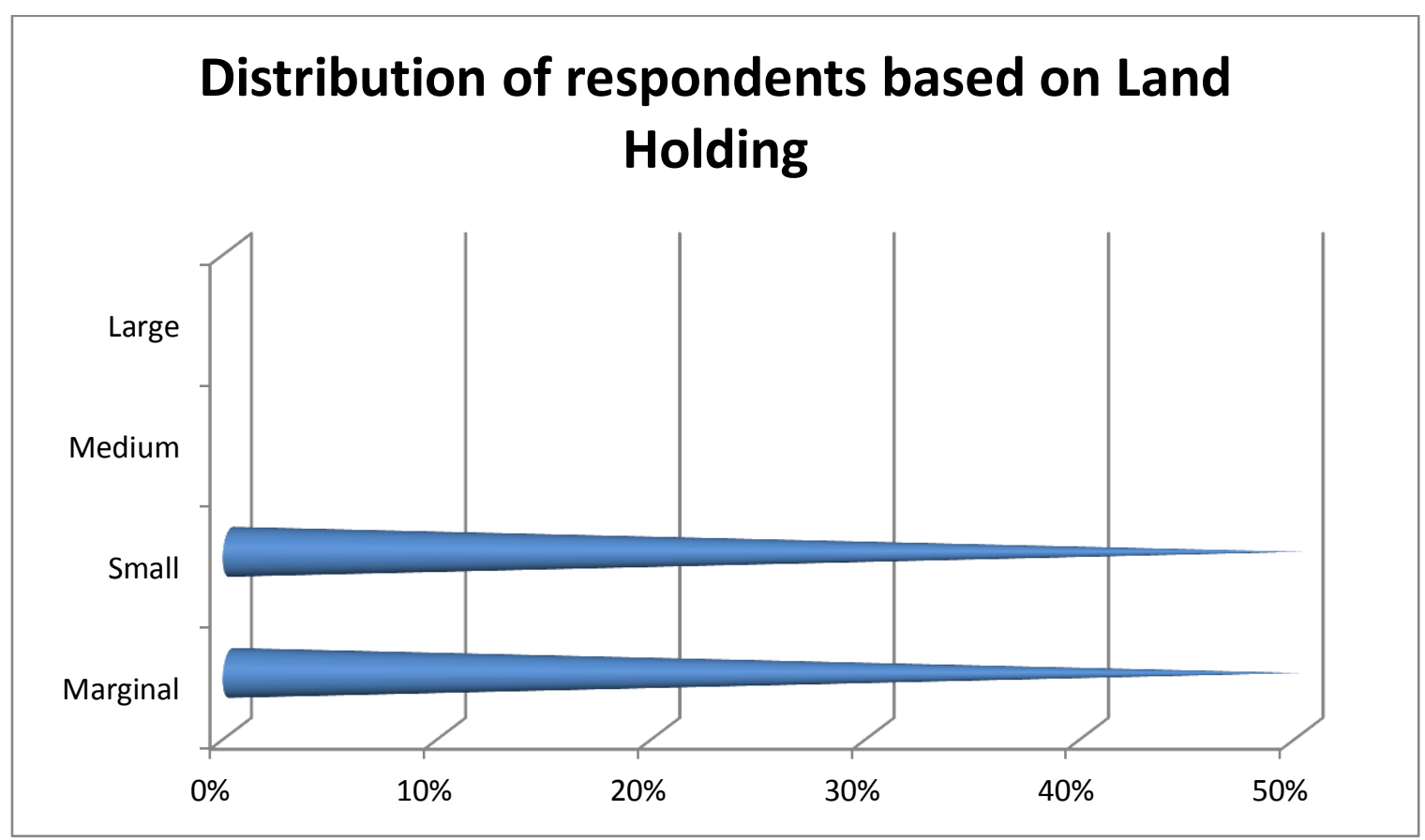

From the above table 7 and fig 7 we can see that equal number of respondents $50 \%$ fall under marginal and small farmers.

\section{Occupation}

Table 8:- Distribution of respondents based on Occupation

\begin{tabular}{|c|c|c|c|}
\hline Sl.no & Occupation & Frequency & Percentage \\
\hline 1. & Farming & 28 & $23.3 \%$ \\
\hline 2. & Farming+ Jobs & 23 & $19.2 \%$ \\
\hline 3. & Farming+ Business & 69 & $57.5 \%$ \\
\hline & Total & 120 & $100 \%$ \\
\hline
\end{tabular}




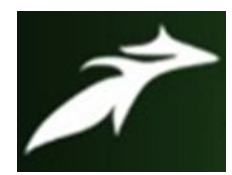

Deeptangshu Sarma et al, International Journal of Advances in Agricultural Science and Technology, Vol.8 Issue.8, August-2021, pg. 147-162

Fig 8:- Distribution of respondents based on Occupation

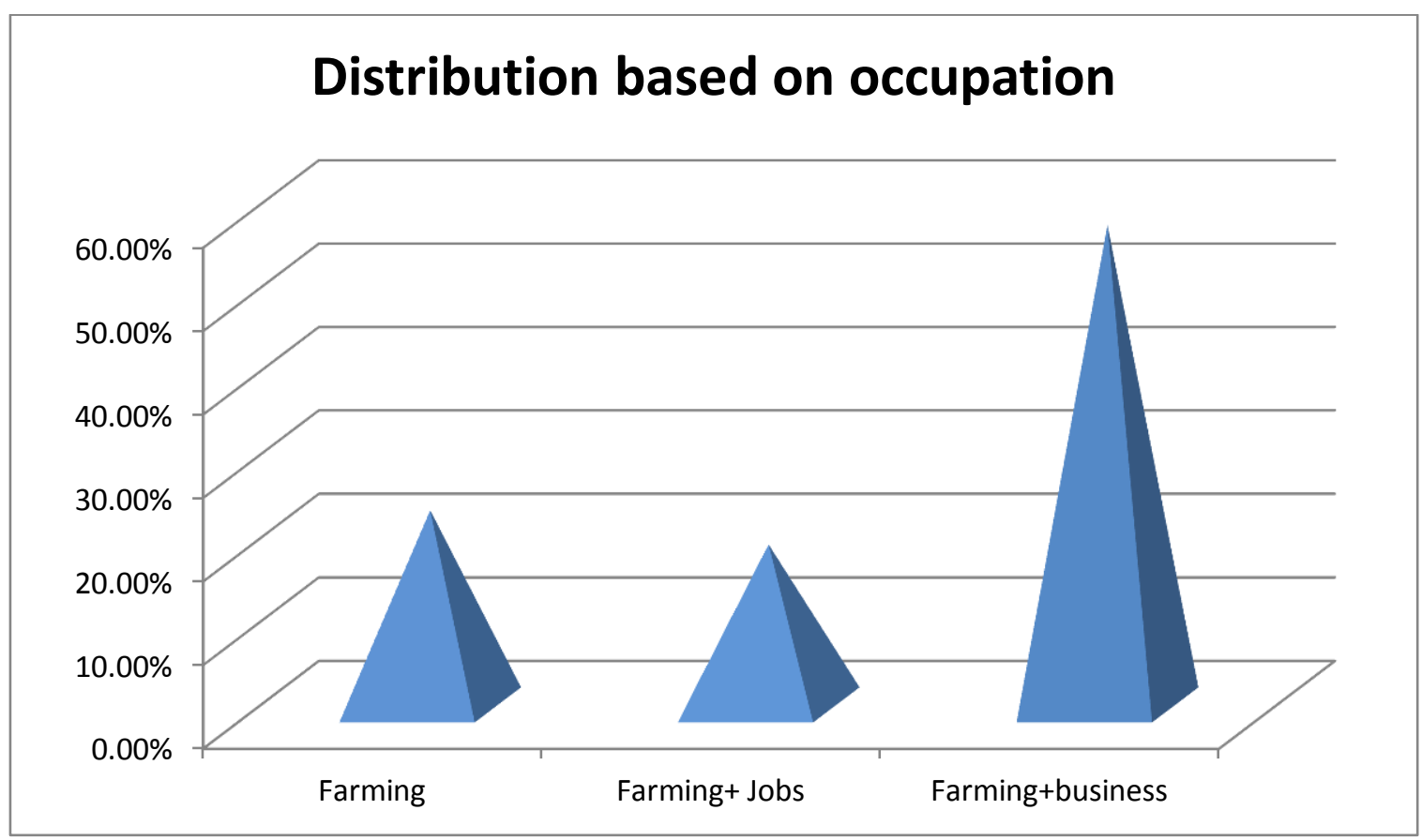

From the table 8 and fig 8 we can observe that $57.5 \%$ of the respondents are involved in Farming as well as business, $23.3 \%$ of them are only involved in farming and finally only $19.2 \%$ of them have a job and does farming.

\section{Farm Power}

Table 9:- Distribution of respondents based on Farm Power

\begin{tabular}{|c|c|c|c|}
\hline Sl.no & Farm Power & Frequency & Percentage \\
\hline 1. & Bullock & 69 & $57.5 \%$ \\
\hline 2. & Tractor & 35 & $29.1 \%$ \\
\hline 3. & Pumpset & 11 & $9.1 \%$ \\
\hline 5. & Others & 5 & $4.1 \%$ \\
\hline & Total & 120 & $100 \%$ \\
\hline
\end{tabular}




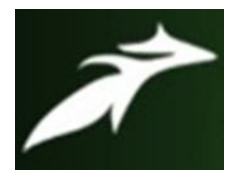

Deeptangshu Sarma et al, International Journal of Advances in Agricultural Science and Technology, Vol.8 Issue.8, August-2021, pg. 147-162

Fig 9:- Distribution of respondents based on Farm Power

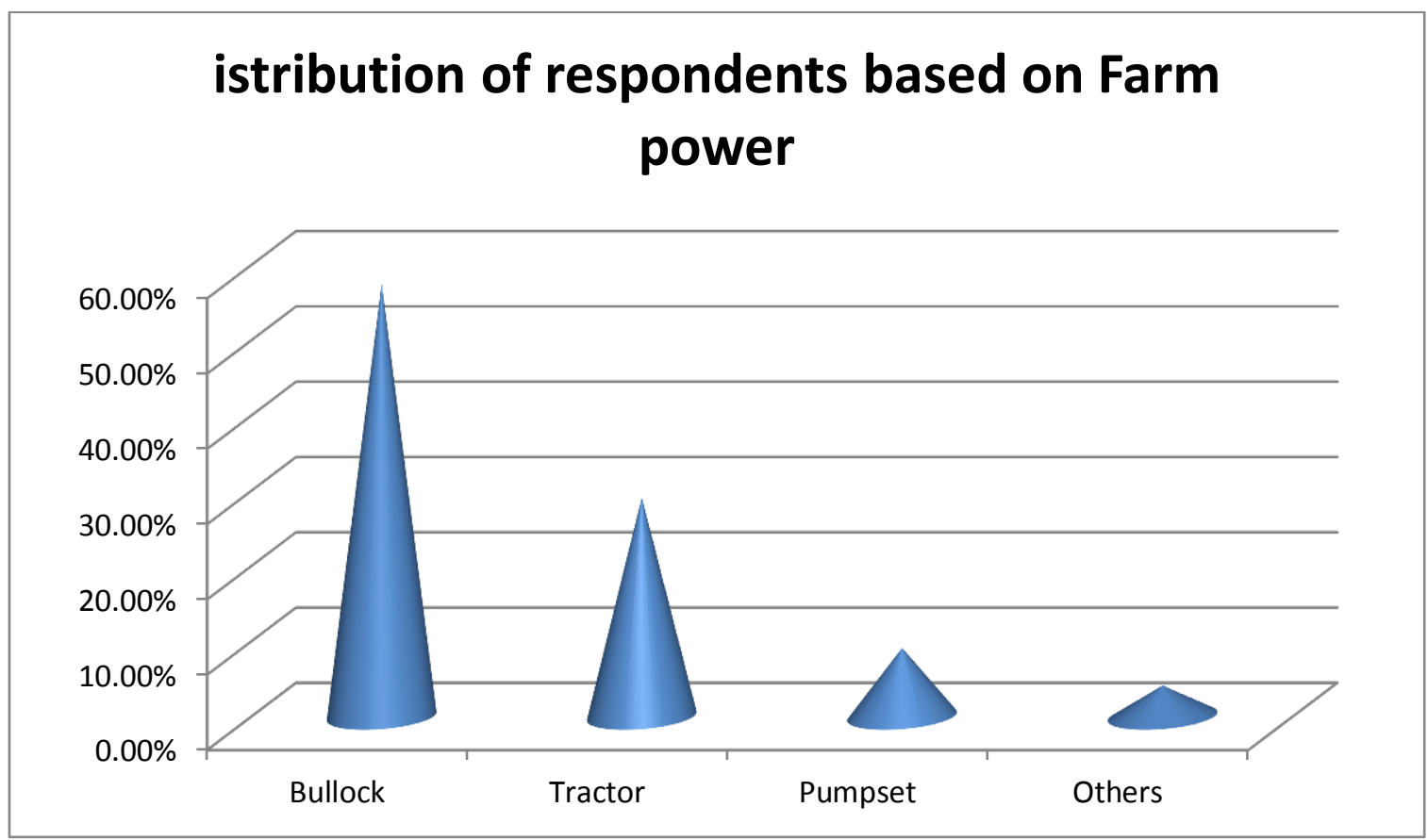

From the table 9 and figure 9 we can observe that $57.5 \%$ of the respondents use bullock, whereas $29.1 \%$ of them used tractor. $9.1 \%$ have pump set. Only $4.1 \%$ have others.

\section{Social Participation}

Table 10:- Distribution of respondents based on social participation

\begin{tabular}{|c|c|c|c|}
\hline Sl.no & $\begin{array}{c}\text { Social } \\
\text { Participation }\end{array}$ & Frequency & Percentage \\
\hline 1. & Gram panchayat & 18 & $15 \%$ \\
\hline 2. & $\begin{array}{c}\text { Co-operative } \\
\text { society }\end{array}$ & 17 & $14.2 \%$ \\
\hline 3. & Self Help Group & 79 & $65.8 \%$ \\
\hline 5. & Youth Club & 6 & $5 \%$ \\
\hline & Total & 120 & $100 \%$ \\
\hline
\end{tabular}




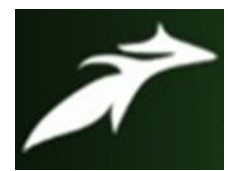

Deeptangshu Sarma et al, International Journal of Advances in Agricultural Science and Technology, Vol.8 Issue.8, August-2021, pg. 147-162

Fig 10:- Distribution of respondents based on social participation

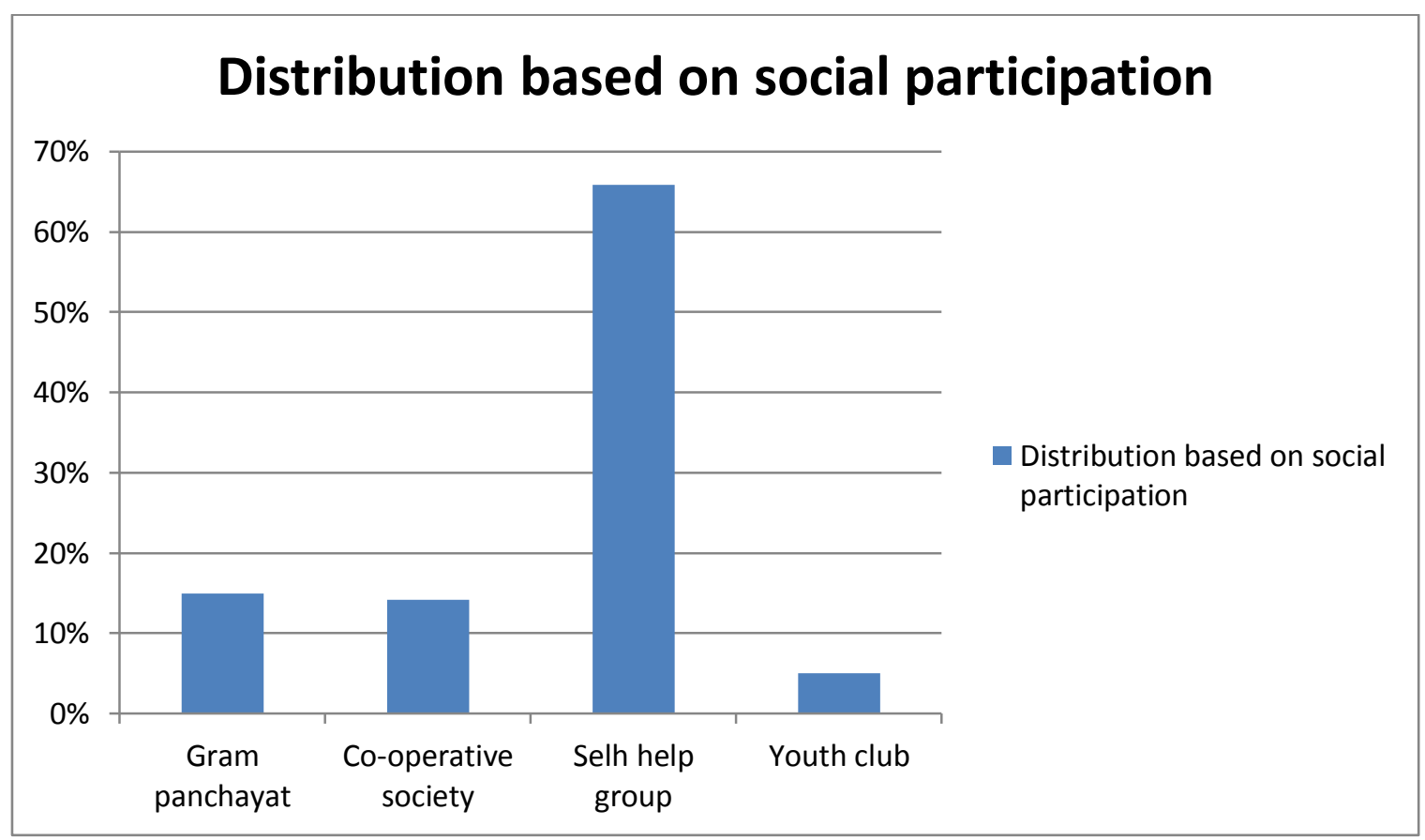

From the table 10 and fig 10 we can conclude that $65.8 \%$ are involved in self help group, $15 \%$ are involved in gram panchayat, whereas $14.2 \%$ are involved in cooperative society, $5 \%$ are involved in youth club.

\section{Material Possession}

Table 11:- Distribution of respondents based on Material Possession

\begin{tabular}{|c|c|c|c|}
\hline Sl.no & Materials & Frequency & Percentage \\
\hline 1. & Bullock cart & 0 & $0 \%$ \\
\hline 2. & Cycle & 44 & $36.6 \%$ \\
\hline 3. & Motorcycle & 70 & $58.3 \%$ \\
\hline 5. & Car & 6 & $5 \%$ \\
\hline & Total & 120 & $100 \%$ \\
\hline
\end{tabular}




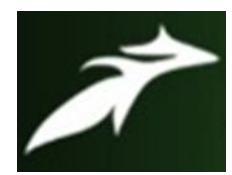

Deeptangshu Sarma et al, International Journal of Advances in Agricultural Science and Technology, Vol.8 Issue.8, August-2021, pg. 147-162

Fig 11:- Distribution of respondents based on Material Possession

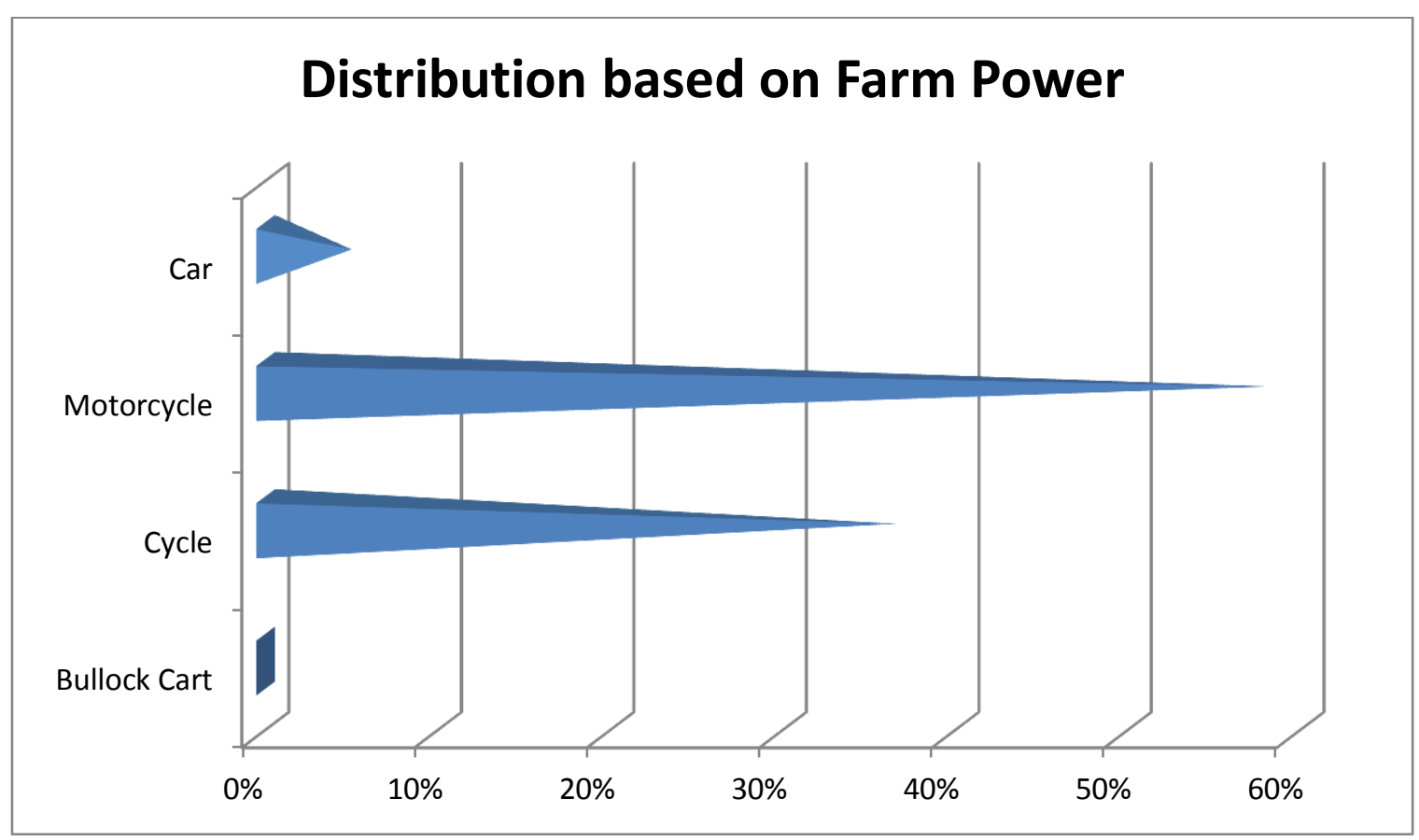

From the table 11 and fig 11 we can observe that majority of the respondents $58.3 \%$ have motorcycle, $36.6 \%$ have cycle whereas $5 \%$ have car.

\section{Mass Media Exposure}

Table 12:- Distribution of the respondents based on mass media exposure

\begin{tabular}{|c|l|l|l|l|l|l|l|}
\hline S.No & Mass media exposure & Always & \multicolumn{2}{l|}{ Sometimes } & \multicolumn{2}{l|}{ Rarely } \\
\hline & & F & P & F & P & F & P \\
\hline 1. & Do you listen to radio? & 0 & $0 \%$ & 21 & $17.5 \%$ & 99 & $82.5 \%$ \\
\hline 2. & Do you watch television & 73 & $60.8 \%$ & 47 & $39.2 \%$ & 0 & $0 \%$ \\
\hline 3. & Do you read newspaper & 41 & $34.2 \%$ & 40 & $33.3 \%$ & 39 & $32.5 \%$ \\
\hline 4. & $\begin{array}{l}\text { Do you search online for } \\
\text { your problem }\end{array}$ & 0 & $0 \%$ & 26 & $21.7 \%$ & 94 & $78.3 \%$ \\
\hline
\end{tabular}




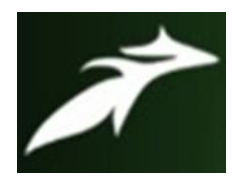

Deeptangshu Sarma et al, International Journal of Advances in Agricultural Science and Technology, Vol.8 Issue.8, August-2021, pg. 147-162

ISSN: 2348-1358

Impact Factor: 6.057

NAAS Rating: $\mathbf{3 . 7 7}$

Fig 12:- Distribution of the respondents based on mass media exposure

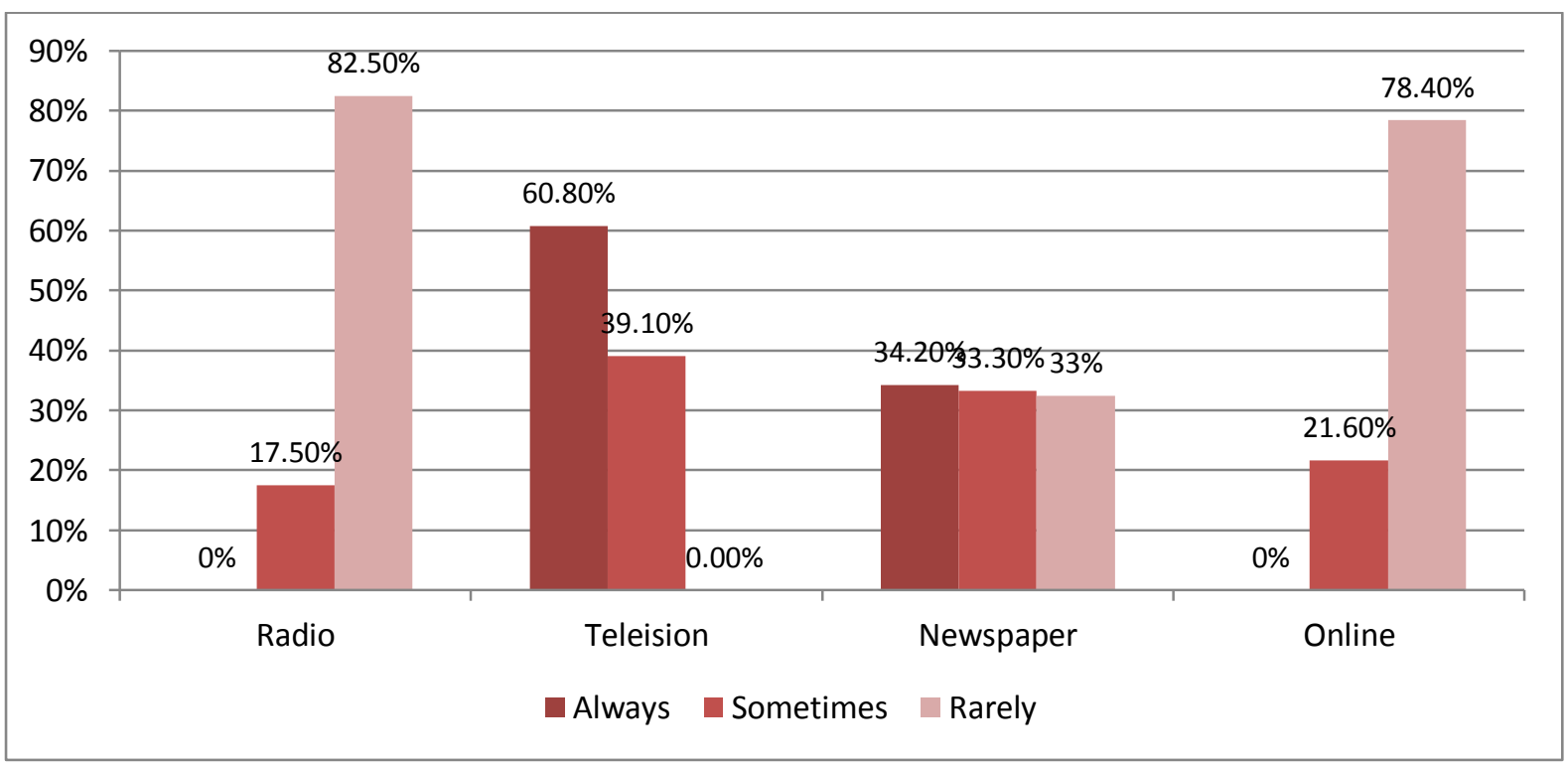

From the above fig 12 we can observe that $17.5 \%$ of the respondents sometimes use radio, whereas $82.5 \%$ rarely use radio. $60.8 \%$ of them always use television, whereas $39.2 \%$ of them sometimes use television. 34.2\% always read newspaper, whereas $33.3 \%$ of them sometimes read newspaper, $32.5 \%$ rarely read newspaper. $21.6 \%$ sometimes use internet to solve problem, whereas $78.4 \%$ rarely use.

\section{Extension Contact}

Table 13:- Distribution of the respondents based on Contact with Extension Personnel

\begin{tabular}{|c|c|c|c|c|c|c|c|}
\hline \multirow[t]{2}{*}{ S.No } & \multirow[t]{2}{*}{ Extension contacts } & \multicolumn{2}{|c|}{ Regularly } & \multicolumn{2}{|c|}{ Occasionally } & \multicolumn{2}{|c|}{ Never } \\
\hline & & $\mathbf{F}$ & $\mathbf{P}$ & $\mathbf{F}$ & $\mathbf{P}$ & $\mathbf{F}$ & $\mathbf{P}$ \\
\hline 1. & $\begin{array}{l}\text { District } \\
\text { Officer }\end{array}$ & 0 & $0 \%$ & 27 & $22.5 \%$ & 93 & $77.5 \%$ \\
\hline 2. & $\mathrm{ADO}$ & 17 & $14.1 \%$ & 22 & $18.3 \%$ & 81 & $67.5 \%$ \\
\hline 3. & Progressive Farmers & 81 & $67.5 \%$ & 39 & $32.5 \%$ & 0 & $0 \%$ \\
\hline 4. & KVK & 0 & $0 \%$ & 19 & $15.8 \%$ & 101 & $84.1 \%$ \\
\hline 5. & VLW & 27 & $22.5 \%$ & 59 & $49.1 \%$ & 34 & $28.3 \%$ \\
\hline
\end{tabular}




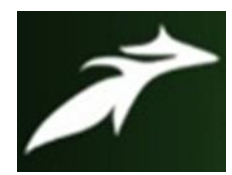

Deeptangshu Sarma et al, International Journal of Advances in Agricultural Science and Technology, Vol.8 Issue.8, August-2021, pg. 147-162

ISSN: 2348-1358

Impact Factor: 6.057

NAAS Rating: $\mathbf{3 . 7 7}$

Fig13:- Distribution of the respondents based on Contact with Extension Personnel

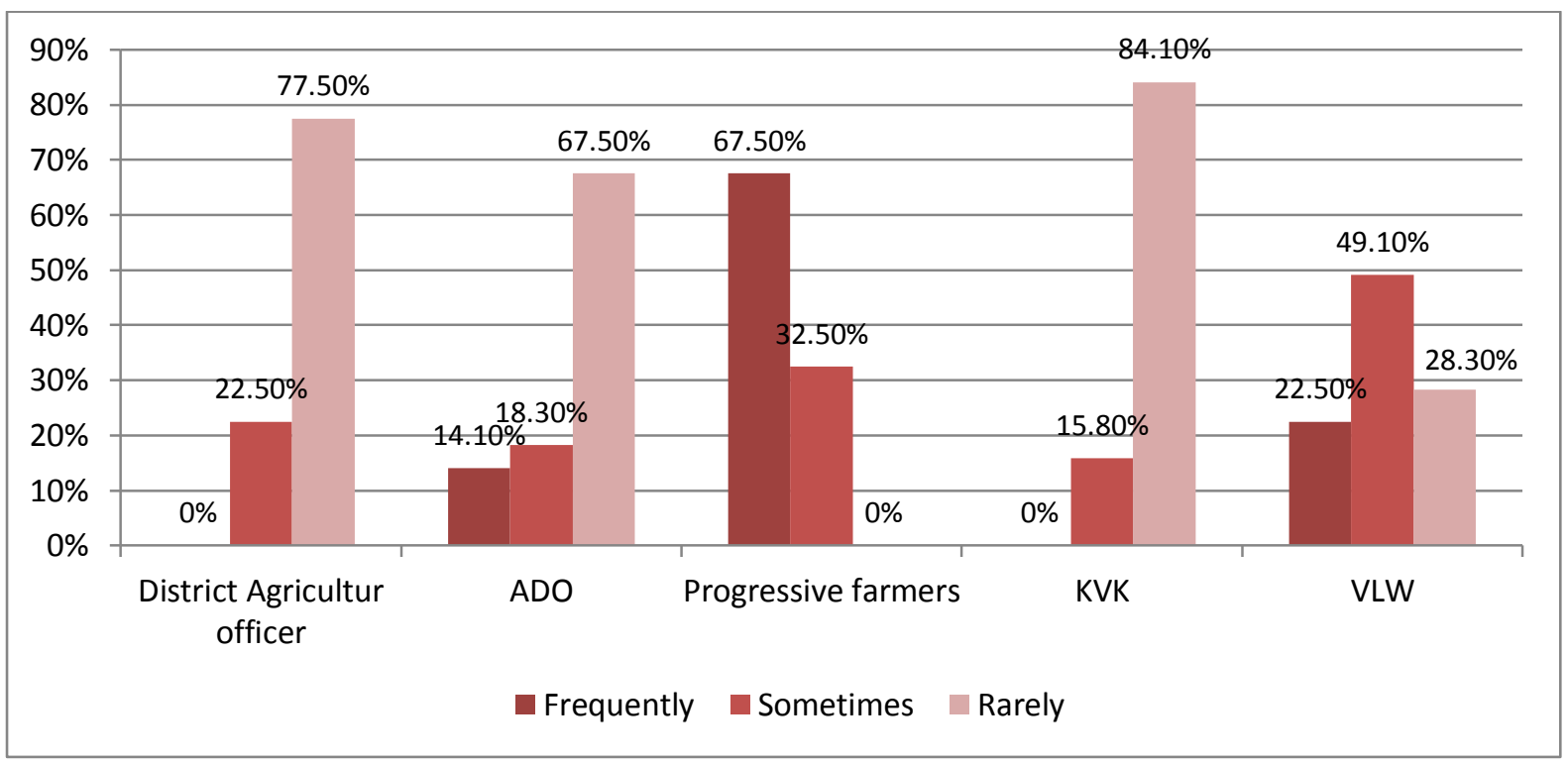

The above table, Table 13 indicates that $22.5 \%$ sometimes interact with district agriculture officers while 77.5 per cent of the respondents rarely interact with the District Agriculture officers. 14.2 per cent of the respondents frequently interact with them. 18.3 per cent Sometimes interact with the ADO and $67.5 \%$ per cent rarely interact with them. $67.5 \%$ frequently interact with the progressive farmers. $32.5 \%$ sometimes are in contact with the progressive farmers. Only $15.8 \%$ of the respondents are sometimes in contact with the scientist of KVK. $84.1 \%$ are rarely in contact. $22.5 \%$ of the respondents are frequently in contact with the village level workers, $49.1 \%$ are sometime in contact with the VLW, whereas $28.3 \%$ are rarely in contact.

\section{Overall SES category}

\begin{tabular}{|c|c|c|c|}
\hline Sl.no & Occupation & Frequency & Percentage \\
\hline 1. & Low & 39 & $32.5 \%$ \\
\hline 2. & Medium & 58 & $48.3 \%$ \\
\hline 3. & High & 23 & $19.2 \%$ \\
\hline & Total & 120 & $100 \%$ \\
\hline
\end{tabular}

\section{Conclusion}

One of the major goals of agriculture development in Assam is to persuade farmers in adopting new technologies. For the development of the country Schedule caste and schedule tribe people must be uplifted. To increase the agriculture production not only large farmers, but marginal and small farmers need to be given more importance, as $86 \%$ of Indian farmers belong to small and marginal category. For making India food sustainable and feed the hundreds of people in the upcoming years more emphasize must be given to small and 


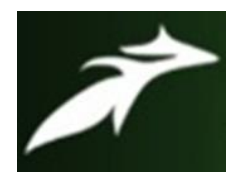

Deeptangshu Sarma et al, International Journal of Advances in Agricultural Science and Technology, Vol.8 Issue.8, August-2021, pg. 147-162

ISSN: 2348-1358

Impact Factor: 6.057

NAAS Rating: $\mathbf{3 . 7 7}$

marginal farmers. From the above study we can conclude that majority of the farmers belonging to small and marginal category falls under medium level of socio economic status. People are most dependent on Bullock for land preparation, whereas farm power is very less. Along they have very less exposure to Mass media and contact with scientist and government officials are quite low. 